\title{
AUTONOMIA E CONSENSO SOBREPOSTO EM RAWLS
}

\author{
AUTONOMY AND OVERLAPPING CONSENSUS IN RAWLS
}

\author{
THADEU WEBER \\ (PUC-RS / Brasil)
}

\begin{abstract}
RESUMO
O texto discute a possibilidade de uma concepção política de justiça ser objeto de um consenso, considerando a autonomia gerada nas condições da "posição original". Examina os pressupostos e os passos que podem conduzir a um consenso sobreposto, tendo em vista sua legitimidade e estabilidade. Chama atenção para uma possível argumentação circular envolvendo o consenso constitucional e o consenso sobreposto.
\end{abstract}

Palavras-chave: Autonomia. Consenso sobreposto. Estabilidade. Consenso constitucional.

\begin{abstract}
This paper discusses the possibility of political conception of justice as object of a consensus, considering the autonomy generated under the conditions of the original position. Examines the assumptions and steps that can lead to an overlapping consensus, in view of its legitimacy and stability. Draws attention to a possible circular reasoning involving the constitutional consensus and overlapping consensus.
\end{abstract}

Keywords: Autonomy. Overlapping consensus. Stability. Constitutional consensus.

\section{Problema}

Se a autonomia se refere à construção dos princípios de justiça, o consenso diz respeito a um possível acordo em torno desses princípios, que constituem a concepção política de justiça. Um dos desafios que se coloca é este: como estabelecer e preservar a unidade e a estabilidade de uma sociedade cooperativa? Mais especificamente: enquanto resultado de um procedimento autônomo, como pode uma concepção de justiça ser objeto de consenso entre diferentes doutrinas abrangentes e razoáveis?

A discussão gira em torno da possibilidade das doutrinas abrangentes e razoáveis endossarem uma concepção política de justiça. ${ }^{1}$ É o problema do consenso sobreposto (overlapping consensus). No entanto, fica claro nas obras de Rawls, que nenhuma dessas doutrinas abrangentes é adequada para ser elevada ao nível de uma concepção política, portanto, capaz de gerar um consenso. Contudo, é preciso contar com o apoio delas. 
Em que consiste, propriamente, o consenso sobreposto? Quais são seus pressupostos? Por que ele somente é possível acerca de uma concepção política de justiça? Por que esta preserva a unidade e a estabilidade de uma sociedade? Essas questões envolvem a questão central: como o liberalismo político se efetiva?

Em primeiro lugar, é preciso salientar que existem dois pressupostos fundamentais na concepção política de justiça de J. Rawls:

$1^{\circ}$ - A concepção normativa de pessoa. Inclui duas capacidades indispensáveis para ser membro de uma sociedade cooperativa: o senso de justiça e a concepção do bem. ${ }^{2}$

$2^{\circ}$ - A idéia de um Estado democrático de direito. A ideia de sociedade bem ordenada comporta uma concepção política e pública de justiça. Esta somente pode ser pensada para uma sociedade democrática, ainda que não liberal. Sociedades não democráticas não são razoáveis.

\section{A supremacia dos valores políticos ${ }^{3}$}

Em se tratando de uma concepção política de justiça estão em jogo tão somente valores políticos. A necessidade dessa restrição se deve ao alcance (à efetivação) de um possível consenso. Em outras palavras: uma concepção política somente pode "conquistar o apoio de um consenso sobreposto" se limitar seu âmbito de abrangência aos valores políticos. ${ }^{4}$ Por que estes valores superam quaisquer outros que possam conflitar com eles? Para Rawls, os valores políticos superam os demais devido ao seu grau de importância, isto é, eles "governam a estrutura básica da vida social [...] e especificam os termos essenciais da cooperação política e social". 5 Ora, os valores que orientam as principais instituições sociais, econômicas e políticas são os mais importantes de uma sociedade cooperativa. São pelo menos os valores sobre os quais um maior número de pessoas pode concordar e possivelmente atingir um consenso. Na justiça como equidade esses valores são expressos pelos princípios de justiça, entre os quais estão os valores de igual liberdade política e social, da igualdade equitativa de oportunidades, da reciprocidade econômica e do respeito mútuo. ${ }^{6}$ Esses valores, por constituírem a estrutura básica da sociedade, são endossáveis pelas doutrinas abrangentes e razoáveis. Disso decorre a estabilidade da justiça como equidade. Não é que outros valores, como os religiosos e morais, não tenham importância. No que coincidem com os valores políticos são igualmente fundamentais; no que não coincidem ficam para ser operacionalizados nas doutrinas abrangentes razoáveis. Há uma fundamental 
autonomia do domínio do político. Os princípios e valores da "justiça como equidade" não dependem de doutrinas morais abrangentes e razoáveis, mas devem poder contar com o apoio delas.

No entanto, a resposta mais convincente para a supremacia dos valores políticos, expressos pela concepção política de justiça, está no fato desta ser "liberal". "Isso significa que ela protege os direitos fundamentais conhecidos e lhes atribui uma prioridade especial. ${ }^{7}$ Também inclui medidas para assegurar que todos os cidadãos tenham meios materiais suficientes para fazer um uso efetivo desses direitos fundamentais". ${ }^{8}$ Com o estabelecimento dos direitos fundamentais e a determinação de sua prioridade, o liberalismo político retira da agenda política as questões que provocam maiores divergências. Os valores políticos expressos pelos princípios políticos de justiça constituem elementos constitucionais essenciais para a cooperação social e por isso são endossáveis pelas doutrinas morais abrangentes, mesmo que por diferentes razões. Com isso, diminuem os possíveis conflitos com outros valores. Os valores da concepção política de justiça são o mínimo essencial e não são incompatíveis com os valores morais e religiosos. O essencial está no estabelecimento da prioridade do $1^{\circ}$ princípio, o dos direitos e liberdades básicos, em relação ao $2^{\circ}$ princípio, o da justiça distributiva.

\section{A estabilidade da "justiça como equidade"}

Rawls é taxativo ao afirmar que uma concepção de justiça precisa preocupar-se com sua própria sustentação. ${ }^{9}$ Para ele a justiça como equidade, como concepção liberal, gera sua estabilidade, pois conta com uma justificação pública e gera um consenso, isto é, é apoiado por doutrinas abrangentes razoáveis, mas não depende delas. Mas como compatibilizar a adesão a uma teoria de justiça para a estrutura básica da sociedade com a diversidade de doutrinas abrangentes e razoáveis? Em outras palavras: pode uma concepção de justiça ser objeto de consenso sobreposto em meio à diversidade de doutrinas abrangentes razoáveis? O fato é que sem a adesão dessas doutrinas não haverá consenso e, por conseguinte, não haverá estabilidade. O núcleo essencial da argumentação do autor gira em torno da seguinte conviç̧ão: cidadãos que convivem em meio a instituições básicas justas desenvolvem o senso de justiça. Isso as torna estáveis. 
Conforme já referido, só é possível um acordo em torno de uma concepção política de justiça. Isso significa que ela somente pode incluir valores de uma cultura política pública de uma sociedade democrática. Nessa sociedade pode-se gerar um consenso que obtenha a adesão dos indivíduos razoáveis sem que estes tenham que abrir mão de suas concepções morais e religiosas. No entanto, uma doutrina abrangente não poderá ser objeto de consenso. Ela professa valores que não se situam no nível do "razão pública". Logo, o problema da estabilidade só pode ser colocado em relação aquilo que é objeto de consenso, o consenso sobreposto. Por quê? Porque a estabilidade exige a adesão dos cidadãos à concepção de justiça por suas próprias razões ou a partir de suas concepções abrangentes e razoáveis. Isso significa que a estabilidade implica na compatibilização da concepção política de justiça com o pluralismo razoável, sem que, no entanto, aquela dependa de uma concepção abrangente razoável que constitui esse pluralismo. Uma concepção política de justiça não pode moldar-se às doutrinas abrangentes razoáveis com o intuito de obter seu apoio. Ela perderia sua autonomia. "Uma concepção de justiça só poderá ser estável (isto é, só poderá gerar a adesão dos indivíduos ao longo do tempo) se contar com algum tipo de justificação pública..."10. Ora, esse tipo de justificação envolve valores eminentes objetivos ou objetiváveis. A mesma interpretação é feita por Luiz B. Araujo quando afirma que a ideia de justificação pública está diretamente conectada com as ideias de estabilidade e legitimidade ${ }^{11}$. O tipo de consenso adotado pelo Liberalismo Político, continua o autor, refere-se a uma justificação "realizada sempre pro tanto, que não procura olhar para, e nem mesmo saber quais são, os valores não políticos das doutrinas compreensivas" ${ }^{\text {"12 }}$. A justificação refere-se apenas aos valores políticos. Uma concepção política de justiça será objeto de adesão e suporte por parte das doutrinas abrangentes razoáveis na medida em que ela conseguir retirar as questões controversas da agenda política e pública, isto é, eliminar os valores não políticos. Em vez de ser abrangente, a concepção política de justiça limita-se às instituições políticas, sociais e econômicas. Portanto, só poderá ser estável se for uma concepção política de justiça. Ora, esta só obterá adesão das concepções abrangentes razoáveis se tratar de valores realmente fundamentais para organizar a cooperação social. Nesse caso importam os valores políticos.

Para o autor, a questão da estabilidade pode ser resumida em dois aspectos: $1^{\circ}$ "As pessoas que crescem em meio a instituições justas [...] adquirem um senso de justiça suficiente, de modo a geralmente agirem de acordo com essas instituições". ${ }^{13}$ Isso pressupõe, obviamente, uma concepção política de pessoa. Sem certas capacidades não se gera acordo. $2^{\circ} \mathrm{O}$ consenso 
sobreposto tem por objetivo uma concepção política de justiça. Do $1^{\circ}$ aspecto resultam instituições estáveis. O senso de justiça dos cidadãos é que garante essa estabilidade. Eles se dispõem a "distribuir justiça entre si no decorrer do tempo". ${ }^{14} \mathrm{O}$ tipo de estabilidade pensado por Rawls refere-se ao resultado da experiência e vivência dos cidadãos em instituições justas. Mas o que são instituições justas? São instituições democráticas. São instituições que garantem a efetivação dos direitos e liberdades fundamentais individuais e sociais, previstos no $1^{\circ}$ princípio. Logo, esses são os elementos constitucionais essenciais a serem assegurados por um Estado democrático de direito, isto é, por um regime constitucional duradouro. Os cidadãos que crescem em meio a instituições justas "adquirem uma lealdade razoável e informada" em relação a essas instituições. ${ }^{15}$ Isso as torna estáveis. É que a justiça como equidade rawlsiana tem como pressuposto, conforme referido, uma concepção normativa de pessoa. O consenso sobreposto se baseia nela, ou seja, pressupõe que a pessoa tenha a capacidade de ter senso de justiça e uma concepção do bem. Sem essas capacidades ou qualidades não se poderia chegar a um acordo político através de uma argumentação pública. Logo, não se poderia assegurar a estabilidade. O segundo aspecto envolve a discussão em torno da qual a justiça como equidade pode assumir o papel de um consenso sobreposto. Isso significa que aqueles cidadãos que "crescem sob instituições básicas justas adquirem um senso de justiça e têm uma fidelidade refletida (reasoned allegiance) por essas instituições no grau suficiente para torná-las estáveis". ${ }^{16}$ Portanto, a justiça como equidade é autosustentável. Vivendo em instituições justas, os cidadãos, dadas suas qualidades morais, adquirirão motivação suficiente para assegurar a estabilidade. A justiça como equidade precisa conquistar o apoio dos cidadãos com suas diferentes doutrinas abrangentes razoáveis. A estabilidade decorre do fato da sociedade ser regulada por um senso público de justiça. Mas e os que não aceitam essa concepção política de justiça ou que defendem valores totalmente diferentes dos valores liberais? Isso não afeta a estabilidade? Certamente não é com sanções que se consegue o endosso. É que a concepção pública de justiça (a justiça como equidade) deve ser apresentada como independente das doutrinas abrangentes e razoáveis. O acordo em torno dela se dá no espaço público. Deve preocupar-se em assegurar direitos e liberdades realmente essenciais, retirando do debate as divergências mais profundas como, por exemplo, valores religiosos e morais. Assim, quando os cidadãos endossam a concepção de justiça a partir de suas doutrinas razoáveis e divergentes, ela, em virtude do acordo atingido, se sustenta por si mesma. As próprias ideias de bem consideradas, para Rawls, devem ser 
constituídas por valores políticos. A restrição a estes valores permite o acordo e este assegura a estabilidade. Portanto, culturas que professam valores diferentes das liberais podem endossar uma concepção política de justiça razoável.

É preciso insistir que a concepção política de justiça deve ser autônoma, no que se refere aos valores que se aplicam às relações políticas. Não pode moldar-se às doutrinas abrangentes para conquistar seu apoio. Não se elabora uma concepção de justiça a partir dessas doutrinas de fato existentes. Isso contraria a equidade na posição original. Uma concepção política autônoma parte da ideia da "sociedade como sistema equitativo de cooperação" e daí infere os "bens primários" necessários para cidadãos livres e iguais e que afirmam diferentes concepções de bem.

\section{O que caracteriza um consenso sobreposto?}

As reformulações efetuadas por Rawls em sua teoria da justiça dão conta de que só há possibilidade de consenso em torno de uma concepção política de justiça. Uma sociedade democrática convive com uma diversidade de doutrinas filosóficas, morais e religiosas, muitas vezes em conflito. $\mathrm{O}$ autor as entende como doutrinas abrangentes razoáveis. Cumpre destacar que o consenso refere-se a essas doutrinas, ou seja, não diz respeito a um "pluralismo em si", mas a um "pluralismo razoável”. Este é próprio de instituições livres e que se fortalecem com o passar do tempo. ${ }^{17} \mathrm{O}$ "pluralismo como tal" admite doutrinas "absurdas e agressivas", incompatíveis para um consenso, portanto, excluídas de uma concepção política de justiça. São impróprias para uma sociedade democrática. Em O Direito dos Povos, Rawls, ao discutir a "idéia de razão pública”, sustenta que as doutrinas abrangentes que não podem sustentar uma sociedade democrática não são razoáveis. ${ }^{18}$ Doutrinas fundamentalistas, formas de aristocracia e os casos de ditadura são exemplos de doutrinas não razoáveis. Com o consenso sobreposto quer mostrar que essas doutrinas abrangentes razoáveis podem endossar "uma concepção política de justiça à base de uma sociedade democrática constitucional cujos princípios, ideais e padrões satisfazem o critério de reciprocidade". ${ }^{19}$ Isso significa que os cidadãos podem afirmar ao mesmo tempo uma concepção política e uma doutrina abrangente razoável. Portanto, uma primeira característica do consenso sobreposto é a sua "adaptação" ao pluralismo razoável e não ao pluralismo em si. É um consenso entre concepções compreensivas razoáveis. A concepção política retira valores políticos dessas doutrinas, isto é, aqueles que podem ser objeto de argumentação pública e sejam 
essenciais para a sociedade cooperativa. É fundamental que a concepção política de justiça tenha o respaldo de um consenso que inclui as doutrinas abrangentes religiosas, filosóficas e morais razoáveis, ainda que conflitantes. Essas doutrinas razoáveis são todas aceitáveis, desde que respeitem os limites dos princípios de justiça. ${ }^{20}$ Por isso que Rawls fala em "consenso sobreposto razoável”. Isso significa que a concepção política de justiça, objeto desse consenso, tem alicerces naquelas doutrinas. ${ }^{21}$ Pode-se observar que o campo de abrangência da Filosofia Política em Rawls, aqui, é claro. Para chegar a um consenso ela deve manter independência e autonomia em relação aos problemas e controvérsias de outras áreas da Filosofia, como por exemplo, os ligados à religião, às questões morais, etc. Essa independência não significa indiferença ou ceticismo. Para obter o respaldo (acima referido) a concepção de justiça deve ocupar-se de valores políticos essenciais e endossáveis.

No entanto, e essa é uma segunda característica, se, por um lado, o consenso se refere a um conjunto de doutrinas abrangentes razoáveis, por outro, não depende de nenhuma delas. Isso significa que a justiça como equidade, como concepção política, é uma concepção que se sustenta por si mesma. É autônoma. Essa autosustentabilidade se deve basicamente a sua extensão: ela se limita aos valores e princípios de uma concepção política e aplica-se somente à estrutura básica da sociedade, isto é, às principais instituições políticas, econômicas e sociais. É isso que demarca também a sua especificidade. É um consenso que, além de poder ser subscrito por uma diversidade de concepções abrangentes razoáveis, recebe a adesão delas por suas próprias razões. É um consenso sobreposto razoável em torno de uma concepção política de justiça. Depois de ter mostrado que a justiça como equidade é uma concepção política e, como tal, autônoma, Rawls mostra que os princípios adotados por ela podem receber o apoio das diversas doutrinas abrangentes razoáveis. Em vista disso pode-se falar em consenso sobreposto. Mas a prioridade do justo sobre o bem está claramente configurada. As concepções do bem são aceitáveis desde que na sua realização estejam em conformidade com a concepção política de justiça.

Em síntese: considerando o pluralismo razoável das sociedades democráticas "é possível gerar um consenso ao que podem aderir os indivíduos razoáveis sem ver-se obrigados a abandonar suas concepções filosóficas, religiosas e morais". ${ }^{22}$ Agora, que essa adesão efetivamente garanta a estabilidade de uma concepção política de justiça, é discutível. Por quê? Porque as doutrinas abrangentes fazem parte da "cultura de fundo" não-pública ${ }^{23}$ e o consenso em torno de uma concepção política é um acordo que se constitui no espaço público, portanto, no 
nível da "razão pública". Ou seja: que estabilidade pode dar uma "cultura de fundo" não-pública (igrejas, associações) a um consenso em torno de uma concepção de justiça que se situa no nível da "razão publica"? Como o não-político pode dar sustentabilidade ao político? ${ }^{24}$ Poder-se-ia dizer que a estabilidade resulta dos valores políticos retiráveis das doutrinas abrangentes. Dessa coincidência se originaria o consenso. Mas isso pressupõe que haja alguma coincidência. Certamente existem sociedades e culturas que defendem valores distintos dos valores políticos liberais. Endossarão esses valores? Por que razões? Para garantir a possibilidade da realização também de seus interesses particulares?

\section{Consenso sobreposto: veracidade ou razoabilidade}

Uma questão polêmica acerca do consenso sobreposto de uma concepção política de justiça diz respeito ao problema da sua veracidade. Uma concepção política que pretende atingir um consenso em meio a doutrinas abrangentes razoáveis tem a pretensão de veracidade ou deve ser indiferente à verdade ou pode conflitar com ela? Deve ser ela uma construção da "razão pública" sem pretensão de veracidade?

Um conflito com a verdade seria absolutamente estranho para a "justiça como equidade". É fundamental entender que os cidadãos podem endossar a concepção política de justiça por diferentes razões, sobretudo a partir de suas próprias doutrinas abrangentes ou concepções do bem. Nesse sentido, pode-se afirmar que elas podem concordar e aceitar os princípios de justiça por serem os mais razoáveis, pois, no essencial, não são incompatíveis com suas convicções. A justiça como equidade não afirma e nem nega uma doutrina religiosa, moral ou filosófica. Se o fizesse as excluiria e não poderia contar com seu apoio. Por isso, em vez de afirmá-las como verdadeiras, as considera como razoáveis. Ela própria (a justiça como equidade) é uma concepção política de justiça razoável, a mais razoável entre as teorias concorrentes. O problema é o acordo político e público. Como chegar a ele em meio a essa diversidade de doutrinas. Considerando que cada cidadão concorda com alguma doutrina abrangente, a justiça como equidade tem a pretensão de atingir um consenso a partir dessas visões abrangentes. Os valores defendidos são apenas os políticos, pois são os mais razoáveis para constituírem os elementos constitucionais essenciais e são objeto de justificação pública. Quando o assunto é justiça, temos que encontrar "uma base de justificação pública" sobre o qual haja concordância e 
isto somente é possível em torno de valores políticos. ${ }^{25}$ É fundamental salientar que a justiça como equidade não tem a pretensão de ser verdadeira, mas, sim, de ser a mais razoável.

Nesse sentido, pode-se dizer que os cidadãos podem, a partir de suas "convicções ponderadas", dentro de um "equilíbrio reflexivo", elaborar uma concepção política de justiça, com o intuito de organizar e orientar a cooperação social. Ora, esta pode ser considerada verdadeira ou razoável a partir das visões abrangentes desses cidadãos. Para uns, verdadeira, para outros, a mais razoável, a mais passível de acordo. É possível gerar um consenso por diferentes vias. Os cidadãos podem aderir à concepção política sem abandonar suas concepções filosóficas, religiosas e morais. Por exemplo, para que um cidadão possa professar livremente sua fé religiosa e os valores a ela inerentes concorda com o estabelecimento das liberdades de pensamento e consciência como direitos fundamentais e, assim, como um dos elementos constitucionais essenciais. É claro que os valores religiosos professados por aquele cidadão não constituem a concepção política de justiça, mas esta pode ser endossada por ele. Para que o consenso seja possível é preciso que se retirem da "agenda política" certas questões polêmicas. É uma concepção política de justiça que vai servir de critério de distinção do que "pode razoavelmente ser retirado da agenda política" do que não pode ser retirado. ${ }^{26}$ Algumas questões polêmicas sempre continuarão presentes. Rawls refere o uso de armas nucleares, como exemplo. De qualquer sorte, para que se possa ter alguma possibilidade de atingir um consenso, as “controvérsias religiosas e filosóficas" não devem entrar na agenda política. Não estão sujeitas à justificação pública, a não ser naquilo que coincidem com os valores políticos. Por isso, não se pode, por exemplo, arrolar argumentos religiosos e morais para justificar uma desobediência civil. Rawls defende uma teoria constitucional da desobediência civil. ${ }^{27}$ Dworkin diverge: razões morais e de ordem religiosa podem, sim, justificar uma desobediência civil. ${ }^{28}$

Mas surge outra questão fundamental, apresentada por Rawls como uma objeção à sua concepção política de justiça: se essa concepção pretende atingir um consenso sobreposto entre doutrinas "gerais e abrangentes", não deveria também ela ser "geral e abrangente"? Como resolver os conflitos referentes à justiça sem uma concepção política abrangente? Não é mais fácil chegar a um acordo em torno de uma doutrina moral abrangente de justiça do que em relação a uma concepção política (restrita) de justiça?

Para o autor americano não é necessário que uma concepção política seja abrangente, embora possa ser parte de uma doutrina abrangente. Ela não decorre, nem contempla valores não- 
políticos. Só os valores políticos constituem elementos constitucionais essenciais. É acerca desses, e somente desses, que se faz necessário um acordo. Os outros devem ser retirados da agenda política. A questão é eminentemente prática: temos que chegar a um acordo sobre valores políticos essenciais, como os direitos e liberdades fundamentais. Temos que pensar na elaboração de uma Constituição de um Estado democrático de direito, considerando o pluralismo razoável. É isso que importa para as instituições políticas e sociais, isto é, para a estrutura básica da sociedade. Mesmo assim, não existem respostas convincentes para todas as questões de justiça política. A restrição a uma concepção política facilitará um acordo e evitará que as questões mais controversas apareçam. Isso aumentará as chances de um consenso. Trata-se de um mínimo essencial para orientar a sociedade cooperativa. Note-se que as ideias de sociedade e pessoa são a base do consenso sobreposto e, portanto, da concepção política de justiça. Sem a capacidade de ter senso de justiça e de ter uma concepção do bem, não há possibilidade da construção de princípios de justiça e muito menos de gerar um consenso em torno deles.

Mas e as culturas que defendem valores totalmente diferentes dos liberais? Será que são tão diferentes que nem alguns dos direitos humanos são comuns? De qualquer sorte, a estabilidade de uma concepção política de justiça está diretamente ligada ao apoio dessas diferentes doutrinas razoáveis. No entanto, impõe-se uma observação crítica conhecida: até que ponto Rawls já não pressupõe os valores políticos liberais ao iniciar a construção dos seus princípios de justiça? Será que começa efetivamente pela posição original ou só se vale dela para justificar os valores políticos da tradição liberal? Não cai no mesmo erro de Kant, de acordo com a crítica de Hegel? Faz toda uma construção do imperativo categórico para justificar o que já é prática vigente em sua comunidade ética, por exemplo, a propriedade ou o depósito. ${ }^{29}$

\section{Consenso constitucional e consenso sobreposto}

O objetivo da teoria rawlsiana é atingir um consenso sobreposto acerca de uma concepção política de justiça, pois é o consenso que sustenta essa concepção. A construção dos princípios de justiça constitui a parte ideal de sua teoria. No entanto, o autor reconhece a enorme dificuldade de realizar tal intento (o consenso). Como chegar a um consenso em torno de uma concepção política de justiça tendo em vista a diversidade de doutrinas abrangentes e razoáveis? Um consenso constitucional não seria um caminho prévio a ser percorrido em vista de um 
consenso sobreposto? Para a elaboração de uma Constituição, que visa organizar a sociedade cooperativa, que tipo de consenso (acordo) se requer? Se o consenso sobreposto é utópico ${ }^{30}$ não seria o caso de se buscar uma alternativa mais modesta e mais realista, considerando que um acordo se faz necessário? Que chances tem um consenso sobreposto de ser atingido? Qual é o ponto de partida? A criação de condições equitativas na posição original? Que tipo de acordo se atinge no procedimento da posição original? Qual é a sua extensão?

$\mathrm{O}$ autor americano reconhece que a idéia de sociedade bem ordenada é pouco realista. O consenso sobreposto é introduzido com o intuito de adequá-la "às condições históricas e sociais de sociedades democráticas" ${ }^{31}$. Rawls indica dois momentos (estágios) para atingir o acordo: "o primeiro termina com um consenso constitucional, o segundo com um consenso sobreposto". ${ }^{32}$ No primeiro estágio o consenso não é "profundo". Os "princípios liberais de justiça", satisfeitos pela Constituição, "são aceitos simplesmente como princípios", e não como se fossem baseados nas "idéias de sociedade e pessoa de uma concepção política". ${ }^{33}$ Num consenso constitucional há concordância apenas sobre alguns direitos e liberdades políticas fundamentais e não sobre direitos e liberdades em geral. Há concordância sobre o direito de voto, a liberdade de expressão, de associação, etc., mas certamente há divergência quanto ao seu conteúdo e limites. O consenso constitucional, segundo Rawls, além de não ser profundo não é amplo: inclui apenas "os procedimentos políticos do governo democrático", e não "a estrutura básica da sociedade". ${ }^{34}$ É um consenso que Rawls chama de restrito e não profundo. Mas é preciso começar com ele. A Constituição é essencialmente um procedimento e a justiça como equidade deve ser entendida como "justiça procedimental". Portanto, o acordo começa como constitucional, para, através deste, tornar-se sobreposto. Não fica claro se o consenso requerido pela posição original já não deveria ser o sobreposto, uma vez que afirma que as partes chegarão a um acordo sobre os valores políticos relevantes. Atingiríamos um acordo apenas sobre os elementos constitucionais essenciais? Será possível e é necessário um acordo além disso?

Como chegar a um consenso acerca dos princípios constitucionais? Como atingir um consenso constitucional estável? Poder-se-ia dizer que todo o processo de formação de um consenso começa por um modus vivendi, passa pelo consenso constitucional, para, possivelmente, atingir um consenso sobreposto? Rawls quer mostrar que a aceitação inicial de uma Constituição que assegura os princípios liberais de justiça vai se transformando, gradualmente, em consenso constitucional, onde esses princípios são endossados. Esse é o resultado da adoção dos princípios 
liberais no procedimento da posição original. A experiência de viver num Estado constitucional que adotou os princípios liberais de justiça gera um consenso de que esses são efetivamente os princípios mais razoáveis a serem adotados. Trata-se de uma espécie de aposta política entre as alternativas possíveis. Pode não haver consenso inicial, mas apenas "aquiescência inicial" de uma constituição, que vai se fortalecendo e consolidando na medida da efetivação dos princípios liberais de justiça originalmente instituídos. É claro que esses princípios são objeto de escolha, portanto, poderiam ter sido outros. Para Rawls, são os princípios liberais os escolhidos no procedimento da posição original e que constituem a concepção política de justiça. São resultado de "juízos ponderados" numa situação de "equilíbrio reflexivo". Ainda que não tenham sido objeto de um acordo inicial amplo, a experiência e a vivência em meio a instituições justas, orientadas por aqueles princípios, se desenvolverão em consenso constitucional e este, como objetivo último, em consenso sobreposto. Todos concordarão que a garantia de alguns direitos e liberdades fundamentais, ainda que restritos, são imprescindíveis para a cooperação social. Se não é possível um consenso sobreposto, que se inicie com a escolha e adoção de valores políticos relevantes, isto é, com um acordo para fins constitucionais ou, antes deste, com um modus vivendi $i^{35}$. Há, portanto, um difícil percurso até atingirmos um consenso sobreposto. De uma simples aceitação inicial dos valores políticos, tendo em vista a necessidade da organização da sociedade cooperativa, alcançamos um consenso constitucional - um acordo que talvez possa resultar em consenso sobreposto. Esse é o objetivo. A escolha e a experiência da vivência numa sociedade cooperativa que adotou os valores políticos liberais criam um consenso constitucional. Este pretende ser um mínimo essencial como garantia institucional da cooperação social. Temos que chegar a um acordo em torno de princípios que devem orientar nossa Constituição política. No entanto, esse consenso tem seus limites. Não diz, por exemplo, o que deve ser feito para solucionar os conflitos de direitos fundamentais e nem explicita seu efetivo alcance. O tipo de acordo que visa superar essa insuficiência é o consenso sobreposto, que está apoiado nas idéias de pessoa e de sociedade de uma concepção de justiça.

Rawls é convicto de que só atingiremos um “consenso constitucional estável” quando as instituições políticas básicas forem reguladas pelos princípios liberais de justiça. Quando isso acontecer, estarão satisfeitos alguns requisitos fundamentais para assegurar a estabilidade do consenso constitucional: 
1. Tendo em vista o pluralismo razoável, os princípios liberais de justiça, quando estão em vigor, fixam "o conteúdo de certas liberdades e direitos fundamentais" e lhes atribuem uma "prioridade especial". ${ }^{36} \mathrm{O}$ estabelecimento desses direitos e de sua prioridade é o que caracteriza a concepção política de justiça como liberal. Ao determinar e definir direitos e liberdades realmente fundamentais, retiram-se esses direitos e liberdades das disputas políticas. Por exemplo: fixada a liberdade de expressão como direito fundamental, ela está fora do cálculo de interesses sociais. Os possíveis conflitos entre direitos fundamentais, no seu efetivo exercício, são resolvidos em sua aplicação. ${ }^{37}$ Para isso existem os estágios legislativo e jurisdicional.

2. Um consenso constitucional estável requer que a aplicação de seus princípios se dê mediante a "razão pública" e livre, isto é, pela argumentação pública. Aliás, a própria construção dos princípios políticos se dá pela argumentação pública. Trata-se de uma argumentação acessível e confiável a todos os cidadãos.

3. As instituições políticas que incorporam os princípios liberais de justiça "tendem a encorajar as virtudes cooperativas da vida política: a virtude da razoabilidade e o senso de justiça, o espírito de compromisso (harmonização) e a disposição (boa vontade) de fazer concessões mútuas". ${ }^{38}$ Rawls recorre à psicologia moral para mostrar que, considerando as capacidades de ter uma concepção de bem e de ter senso de justiça, os cidadãos, quando acreditam em instituições justas, se esforçarão para fortalecê-las. A confiança mútua em instituições justas cria estabilidade para uma Constituição. Nesse caso, as próprias concepções morais abrangentes dos cidadãos se alteram na direção da aceitação dos princípios constitucionais. Quando a cooperação social está baseada no respeito mútuo, as liberdades e oportunidades fundamentais serão reconhecidas publicamente. Com isso as "virtudes políticas" se desenvolvem cada vez mais. ${ }^{39}$

A questão fundamental que envolve os dois tipos de consenso (o constitucional e o sobreposto) é esta: pressupondo que iniciemos por um consenso constitucional, como poderia este vir a tornar-se consenso sobreposto? O consenso sobreposto tem por base uma concepção política de justiça que se apóia em duas ideias fundamentais: a ideia de sociedade e de pessoa. Por isso que é mais profundo que o consenso constitucional. Não se aplica somente aos fundamentos constitucionais, mas à "estrutura básica da sociedade". A Constituição é uma das instituições dessa estrutura. Mesmo que seja somente possível uma aproximação do consenso sobreposto, Rawls indica alguns aspectos que levam o consenso constitucional a um consenso sobreposto: esses aspectos estão relacionados com a profundidade, a extensão e a especificidade. 
Quanto à profundidade: o consenso sobreposto tem por base uma concepção política de justiça que, por sua vez, se apóia nas ideias de sociedade e de pessoa e é passível de justificação pública. Um consenso constitucional efetivo força "grupos políticos" ao diálogo e a participarem do "fórum público da discussão política". Diferentes doutrinas abrangentes são levadas a ampliar suas visões restritas, a explicitá-las e a justificá-las para um público mais amplo. Isso os leva a formular princípios e endossar os valores políticos que constituem uma concepção política de justiça. Em outras palavras: na medida em que as doutrinas abrangentes razoáveis convergirem no referente aos valores políticos, pode-se encontrar uma concepção política comum a todos. Luiz Bernardo Araújo diz ser a concepção política de justiça "extraída de dentro das diferentes doutrinas, afirmadas pelos cidadãos, mas isso é feito 'mapeando'-se os valores políticos de cada uma delas". ${ }^{41}$ Um consenso constitucional restrito vai gradualmente ampliando seu foco na direção de um consenso sobreposto.

Quanto à extensão: o consenso sobreposto não se restringe aos "procedimentos democráticos", mas envolve a estrutura básica da sociedade como um todo. Para o autor americano, o "consenso constitucional puramente político e procedimental" é muito restrito. ${ }^{42} \mathrm{~A}$ Constituição não pode ser vista como simples procedimento. Além disso, não basta que sejam asseguradas apenas as liberdades de expressão e de pensamento políticas, mas é necessário instituir uma "legislação fundamental que garanta as liberdades de consciência e pensamento em geral", bem como outras liberdades fundamentais, como a liberdade de associação. Além disso, acrescenta Rawls, "requerem-se medidas que assegurem que as necessidades básicas de todos os cidadãos sejam satisfeitas, de modo que todos possam participar da vida política e social". ${ }^{43}$ Referindo-se especificamente à satisfação dessas necessidades, o autor afirma que "o elemento constitucional essencial em questão é o de que, abaixo de certo nível de bem-estar material e social, e de treinamento e educação, as pessoas simplesmente não podem participar da sociedade como cidadãos, e muito menos como cidadãos iguais". ${ }^{44}$ Isso indica que a concepção política de justiça envolve não apenas direitos e liberdades fundamentais individuais. Inclui, também, os sociais, como a educação, habitação e a saúde. Fica claro que o consenso sobreposto, que começa com o consenso constitucional, é mais amplo e mais profundo do que este. Envolve e requer que, no exercício da cidadania, sejam assegurados princípios e valores políticos mais amplos. Deve-se salientar que para o autor "os direitos, as liberdades e os pensamentos incluídos num consenso constitucional" incluem uma "parte limitada das questões políticas fundamentais que serão 
debatidos". ${ }^{45}$ Certamente existem outros elementos a serem considerados. Sempre haverá forças políticas da sociedade querendo emendar a Constituição ou insistirão que outros elementos essenciais nela deveriam estar assegurados. Que uma Constituição deva contemplar esses elementos será objeto de argumentação e acordo.

Quanto à especificidade: o objeto do consenso sobreposto é uma concepção política de justiça e os valores que a constituem são os políticos. A justiça como equidade parte da ideia de sociedade como sistema equitativo de cooperação e se apóia na concepção política de pessoa (como livre e igual). A concepção política de justiça é elaborada a partir dessas ideias (a sociedade como sistema equitativo de cooperação e a de pessoa como livre e igual). Essa concepção de justiça é o foco do consenso sobreposto. É importante salientar que o consenso constitucional, quando orientado pelas ideias políticas liberais, conduz ao consenso sobreposto e, mesmo que este nunca seja atingido plenamente, continua como objetivo visado. É preciso que um conjunto de direitos e liberdades fundamentais seja assegurado, mesmo que em torno dos quais não haja consenso pleno. Por isso que acordamos os elementos constitucionais realmente essenciais. Obtido um consenso constitucional, estará lançada a base para o consenso sobreposto entre doutrinas morais abrangentes, tendo em vista uma concepção política de justiça. Embora o objeto do consenso seja uma concepção política de justiça, as concepções abrangentes razoáveis podem aderir a ela por diferentes razões. Essa adesão lhe dá estabilidade.

Importante salientar que não é qualquer sociedade que pode ter a pretensão de atingir o consenso sobreposto. Somente uma sociedade democrática, entendida aqui como aquela marcada pelo pluralismo razoável, isto é, pela coexistência de uma diversidade de doutrinas abrangentes razoáveis, é que pode objetivar tal consenso. Não é, portanto, qualquer pluralismo que importa, como é o caso do que admite doutrinas "absurdas e agressivas".

No entanto, Rawls parece não se livrar de certa ambigüidade ou até mesmo de uma argumentação circular. Por um lado, o consenso constitucional parece pressupor o consenso sobreposto, pois para elaborar uma Constituição ${ }^{46}$ deve fazê-lo a partir de princípios de justiça, constituídos por determinados valores políticos e acordados na posição original (procedimento). Portanto, o consenso constitucional já pressupõe a aceitação (acordo) dos princípios liberais de justiça. Por outro lado, Rawls sustenta que o consenso constitucional conduz ao consenso sobreposto. Qual é efetivamente o ponto de partida? Trata-se apenas de uma questão procedimental ou há um conteúdo pressuposto? Por um lado, parece tratar-se de um consenso 
sobreposto, na medida em que se refere à construção dos princípios e, por outro, de um consenso constitucional, na medida em que se refere a sua aplicação. Um (o sobreposto) é o ideal, o outro (o constitucional) o possível. Daí a ambigüidade: o consenso constitucional conduz ao consenso sobreposto, mas, ao mesmo tempo, pressupõe um acordo em torno dos princípios políticos de justiça (procedimento de construção). A sequencia sugerida por Rawls, que parte do modus vivendi, passa pelo consenso constitucional e vai até o consenso sobreposto, não está clara.

$\mathrm{Na}$ prática, e para ser mais realista, temos que fazer escolhas no que se refere aos princípios que devem orientar a elaboração de uma Constituição. Trata-se de um acordo inicial, que pode ter como base um modus vivendi. Requerem-se "juízos ponderados" numa situação de "equilíbrio reflexivo". A experiência e a vivência em meio a instituições justas, orientada por aqueles princípios (que no caso seriam os princípios liberais) fortalecem e consolidam uma Constituição política, produzindo um consenso. $\mathrm{Na}$ prática, temos dois níveis (tipos) de procedimento: 1) O da posição original, cujo resultado são os princípios de justiça. É a justiça procedimental pura. O procedimento é justo porque equitativo e, portanto, com resultado justo. 2) O procedimento da Constituição, que tem como resultado o conjunto da legislação, que pode não ser justo, ainda que o procedimento tenha sido corretamente aplicado. É a justiça procedimental imperfeita. O recurso procedimental adotado - a regra da maioria - pode produzir um resultado injusto, isto é, leis injustas. Portanto, se os princípios são justos, as leis podem não ser. Assim exposto, a aplicação dos princípios de justiça à Constituição pressupõe um acordo no contrato originário, ou seja, pressupõe um consenso sobreposto. Qual é, então, o papel da Constituição? Concretizar os princípios, consolidando-os?

\section{Autonomia e consenso sobreposto}

A autonomia refere-se ao processo de construção dos princípios de justiça que constituem o objeto do consenso sobreposto. Sua palavra de ordem é a justificação pública. Um possível acordo acerca de uma concepção política de justiça tem como pressuposto o exercício do direito de autolegislação dos cidadãos de uma sociedade democrática.

$\mathrm{Na}$ concepção rawlsiana, a autonomia é gerada pelas condições impostas à "posição original". A legitimidade dos princípios escolhidos provém da efetivação dessas condições: de um procedimento justo resultam princípios justos. Tendo em vista que o consenso se dá em torno 
de uma concepção política de justiça, a discussão deve concentrar-se nas condições de possibilidade da autonomia política. Pressupondo as qualidades morais das pessoas (senso de justiça e concepção do bem), a autonomia se expressa na possibilidade que os cidadãos têm de "formular, revisar e procurar concretizar uma concepção do bem e de deliberar de acordo com ela" ${ }^{47}$ Ora, o consenso é gerado em meio a um pluralismo razoável. Pressupõe condições equitativas. Dessa forma, uma concepção de justiça precisa do apoio das doutrinas abrangentes e razoáveis e, portanto, de diferentes concepções do bem. Os cidadãos devem poder aderir aos valores políticos dessa concepção de justiça por diferentes razões, que incluem suas concepções do bem. Isso é autonomia e gera estabilidade numa sociedade cooperativa.

A explicitação do conceito de autonomia em Rawls nos reporta ao que ele chama de “justiça procedimental pura". Esta implica na possibilidade das partes fazerem suas escolhas no que diz respeito aos princípios de justiça sem dependerem de algum princípio de direito e justiça previamente dado. Não dependem de nenhum ponto de vista externo a sua própria posição. Isso mostra que o consenso é efetivamente construído de forma autônoma, com a adesão das doutrinas abrangentes e razoáveis. De um procedimento justo, isto é, equitativo, origina-se um resultado justo. É claro que, mais uma vez, está pressuposta a concepção normativa de pessoa, isto é, a capacidade de ter senso de justiça e desenvolvê-lo e a capacidade de ter uma concepção do bem. Sem isso não haveria autonomia e nem acordo. É a concepção normativa de pessoa que viabiliza o projeto político rawlsiano. Sem as "capacidades morais" não há exercício da autonomia e, por conseqüência, não haverá consenso. É preciso salientar que a justiça procedimental pura refere-se apenas as condições da posição original, ou seja, à construção dos princípios de justiça e não a sua aplicação nos estágios posteriores.

É importante enfatizar que, em tese, o procedimento da posição original é justo porque efetuado em condições equitativas, ou seja, as partes que constroem os princípios de justiça estão simetricamente situadas. É preciso, portanto, que sejam criadas condições favoráveis ao exercício da autonomia, das quais possa resultar um consenso. Daí a função do véu da ignorância. Contando com as "qualidades morais" das pessoas e as condições da posição original, é possível realizar tal intuito. Para que o resultado do procedimento adotado seja justo (o consenso em torno dos princípios da justiça) é preciso que o procedimento ocorra dentro das condições do equilíbrio reflexivo. É nessa construção e seleção que as partes são autônomas ou, como escreve o autor americano, elas são "agentes de um processo de construção". ${ }^{48}$ Nesse processo não são 
determinadas por nenhum princípio de justiça previamente dado. Não são determinadas pelas doutrinas abrangentes e razoáveis, mas podem chegar a um acordo acerca de uma concepção de justiça razoável apoiada por elas. O consenso é atingível na medida em que a concepção política de justiça é endossável por aquelas doutrinas. Pode-se observar que autonomia, consenso e estabilidade estão intrinsecamente imbricados. O que gera estabilidade é o consenso e este se constrói em virtude de escolhas autônomas e de razões que de alguma forma incorporam as diferentes concepções de bem. Essa é a parte ideal da teoria da justiça de Rawls.

O mais significativo em tudo isso é que há dois níveis no exercício da autonomia: das partes (enquanto representantes) e dos cidadãos. As partes são autônomas para fazer um acordo sobre os princípios de justiça, dentro dos limites da posição original; os cidadãos são autônomos para realizar suas concepções do bem, nos limites dos princípios de justiça. Isso mostra que os cidadãos reconhecem os princípios de justiça como aqueles que seriam escolhidos se estivessem situados nas condições da posição original. Isso porque são endossáveis pelas suas doutrinas abrangentes e razoáveis (suas concepções do bem), ainda que por diferentes razões. Reconhecer e agir de acordo com os princípios escolhidos é reconhecer a justiça do procedimento adotado. A autonomia implica na possibilidade de promover nossa concepção do bem em consonância com os princípios de justiça, uma concepção pública de justiça. É importante evidenciar que esta é elaborada para a estrutura básica da sociedade e por isso pode e deve ser endossada por doutrinas abrangentes e razoáveis, por vezes, em conflito. Ao priorizar o que é relevante para um acordo político, estamos facilitando o endosso das diferentes doutrinas abrangentes e razoáveis. Sem essa restrição não há consenso (acordo) e sem consenso não há estabilidade.

É fundamental, portanto, que uma concepção de justiça tenha o apoio das doutrinas abrangentes razoáveis. Para obtê-lo não pode ela ser abrangente. Não haveria acordo possível. Ora, este é imprescindível para a estabilidade. Observe-se: ainda que não abrangente, a concepção de justiça prima pela razoabilidade. Cidadãos razoáveis (com senso de justiça) constroem uma concepção de justiça razoável e, como tal, passível de consenso. Os cidadãos aceitam livremente as restrições do razoável. Autonomia indica capacidade de promover nossa concepção do bem na medida em que for compatível com os princípios de justiça. Nisso revelamos nossa natureza de seres racionais e razoáveis. Isso nos aproxima de Kant.

Como contemplar e compartilhar a multiplicidade de culturas? Considerando o senso de justiça dos cidadãos e a restrição aos valores políticos, é possível um acordo em torno de 
princípios de justiça que definam, pelo menos, os elementos constitucionais essenciais. Isso indica que o consenso atingido é o constitucional (por mais restrito que possa parecer) e isso, por necessidade prática. Poderá vir a tornar-se um consenso sobreposto? É a parte ideal da teoria da justiça de J. Rawls. 


\section{Notas}

${ }^{1}$ Abreviações das obras de Rawls: TJ A Theory of Justice; PL Political Liberalism; JFR Justice as Fairness, a restatement; JD Justiça e Democracia. Rawls fala em doutrinas gerais e abrangentes ou simplesmente em doutrinas abrangentes (compreensíveis) razoáveis. Gerais porque se aplicam a uma variedade de temas e a um leque amplo de objetos; abrangentes porque "compreendem concepções daquilo que tem algum valor na vida humana" (JD p. 255), como ideais de caráter pessoal, de amizade, das relações familiares, etc. Essas doutrinas abrangentes (religiosas, morais e filosóficas) fazem parte do que Rawls chama de "cultura de fundo" da sociedade civil. Não constituem o âmbito do político, mas fazem parte da cultura da vida cotidiana. Ver, também, PL p. 58.

${ }^{2}$ Sobre esse assunto, ver PL p. 19.

${ }^{3}$ Os valores políticos são de dois tipos: a) Os valores da justiça política. São os valores enunciados pelos princípios de justiça: igual liberdade política e civil, a igualdade de oportunidades, a igualdade social etc. b) Os valores da razão pública. Referem-se às "diretrizes da indagação pública que tornam essa indagação livre e pública", as virtudes da razoabilidade e o dever de civilidade (cf. PL p. 224).

${ }^{4}$ PL, p. 15.

${ }^{5}$ PL, p. 139.

${ }^{6}$ Cf. PL, p. 139.

${ }^{7}$ Rawls, em suas principais obras, apresenta diferentes listas de liberdades básicas que, no essencial, coincidem. Essas listas incluem a liberdade de pensamento e de consciência, as liberdades políticas (direito de votar e de participar da política), a liberdade de associação, os direitos e liberdades especificados pela liberdade e integridade da pessoa, os direitos e liberdades abarcadas pelo estado de direito (cf. JFR p. 44 e TJ p.61).

${ }^{8}$ PL, p. 156 e 157.

${ }^{9}$ Cf. JFR, p. 124.

10 Silveira, Pablo da. La Teoria Rawlsiana de La Estabilidade: overlapping consensus, razón pública y discontinuidad. IN: Justiça como equidade. p. 348.

${ }^{11}$ Cf. ARAUJO, Luiz Bernardo. Uma questão de justiça: Habermas, Rawls e Macintyre. IN: Justiça como equidade. p. 217.

${ }^{12}$ ARAUJO, Luiz Bernardo. Uma questão de justiça: Habermas, Rawls e Macintyre. IN: Justiça como equidade. p. 217.

${ }^{13}$ PL, p. 141.

${ }^{14}$ PL, p. 142.

${ }^{15}$ JFR, p. 264.

${ }^{16}$ PL, p. 142.

${ }^{17}$ Em Justiça e Democracia, Rawls afirma que o "fato do pluralismo", que aqui deve ser entendido como pluralismo razoável, é uma "característica permanente da cultura pública das democracias modernas" e não uma "simples condição histórica que deve desaparecer rapidamente” (JD p. 251 e 252). 
${ }^{18}$ Cf. RAWLS, J. O Direito dos Povos, p. 226.

${ }^{19}$ RAWLS, J. O Direito dos Povos, p. 226.

${ }^{20}$ Cf. JD, p. 261.

${ }^{21}$ Cf. JFR, p. 32.

${ }^{22}$ Silveira, Pablo da. La Teoria Rawlsiana de La Estabilidad: overlapping consensus, razón pública y discontinuidad p. 346.

${ }^{23}$ Cf. PL, p. 220.

${ }^{24}$ Sobre esse tema, ver artigo de Manfredo A. de Oliveira, "O Debate acerca da Fundamentação de uma Teoria da Justiça: Rawls e Habermas”. IN: Justiça como Equidade. p.94 e 95. O autor apresenta a crítica de Habermas a Rawls no que se refere a idéia de que "uma concepção pública de justiça possa receber autoridade moral [...] de motivos não-públicos".

${ }^{25}$ PL, p. 150.

${ }^{26}$ PL, p. 151.

${ }^{27}$ Sobre esse assunto, ver $A$ Theory of Justice, capítulo VI, principalmente $\S 55$.

${ }^{28}$ Ver Levando os Direitos a Sério, cap. 08.

${ }^{29}$ Ver T. Weber. Ética e Filosofia Politica, p. 104.

${ }^{30}$ Rawls chama a atenção para a difículdade de se atingir tal consenso ou de mantê-lo estável (cf. JD p. 277).

${ }^{31}$ JFR, p. 32.

${ }^{32}$ PL, p. 158.

${ }^{33}$ PL, p. 158.

${ }^{34}$ PL, p. 159.

${ }^{35}$ Pablo da Silveira diz que Rawls "sugere que historicamente existe uma seqüência" que conduz o modus vivendi ao consenso sobreposto. IN: Justiça como Equidade, p. 349.

${ }^{36}$ PL, p. 161, também JD, p. 280.

${ }^{37}$ Sobre a aplicação dos princípios de justiça, em seus quatro estágios, ver A Theory of Justice, § 31 .

${ }^{38}$ PL, p. 163.

${ }^{39}$ Cf. JD, p. 283.

${ }^{40}$ PL, p. 165.

${ }^{41}$ ARAUJO, Luiz Bernardo. Uma questão de justiça: Habermas, Rawls e Macintyre. IN: Justiça como Equidade: fundamentação e interlocuções polêmicas (Kant, Rawls, Habermas), p. 217.

${ }^{42}$ PL, p. 166.

ethic@-Florianópolis, v. 10, n. 3, p. 131 -153, Dez. 2011. 
${ }^{43}$ PL, p. 166.

${ }^{44}$ PL, p. 166.

${ }^{45}$ PL, p. 166.

${ }^{46}$ Podemos pensar aqui no segundo estágio de aplicação dos princípios de justiça expostos em $A$ Theory of Justice $\S 31$.

${ }^{47}$ PL, p. 72.

${ }^{48}$ JD, p. 54. 


\section{Referências Bibliográficas}

ARAÚJO, Luiz Bernardo Leite. “Uma questão de justiça: Habermas, Rawls e Macintyre”. IN: Justiça como Equidade: Fundamentação e interlocuções polêmicas (Kant, Rawls, Habermas). Florianópolis (UFSC): Editora Insular, 1998.

SILVEIRA, Pablo da. "La Teoria Rawlsiana de La Estabilidad: overlapping consensus, razón pública y discontinuidad". IN: Justiça como Equidade: Fundamentação e interlocuções polêmicas (Kant, Rawls, Habermas). Florianópolis (UFSC): Editora Insular, 1998.

DWORKIN, R. Levando os direitos a sério. São Paulo: Martins Fontes, 2000.

OLIVEIRA, Manfredo. "O Debate acerca da Fundamentação de uma Teoria da Justiça: Rawls e Habermas". IN: Justiça como Equidade: Fundamentação e interlocuções polêmicas (Kant, Rawls, Habermas). Florianópolis (UFSC): Editora Insular, 1998.

RAWLS, J. A Theory of Justice. Cambridge: Harvard University Press, 1997.

. Political Liberalism. New York: Columbia University Press, 2005.

. O Direito dos Povos. São Paulo: Martins Fontes, 2004.

. Justice as Fairness: a restatement. Cambridge: Harvard University Press, 2001.

. Justiça e Democracia. São Paulo: Martins Fontes, 2000.

. O Liberalismo Político. São Paulo: Ática, 2000.

WEBER, Thadeu. Etica e Filosofia Politica: Hegel e o formalismo kantiano. Porto Alegre: EDIPUCRS, 2009. 